\title{
OLIVEIRA VIANNA E A CONSTITUIÇÃO DE 1934
}

Nelson Oscar de Souza

1. Lembrar: Afonso Arinos de Mello Franco, em sua obra clássica, ${ }^{1}$ acentuava que a história completa da Constituição de 1934 ainda está por escrever.

De outro lado, Pontes de Miranda, em seus Comentários, entendeu que aquela, na época, era a mais complexa de todas as Constituições vigentes no continente sulamericano. $^{2}$

2. Acentuar: antes da participação na Comissão que deveria oferecer o anteprojeto à Constituinte, Oliveira Vianna tivera experiência anterior, em 1932, ocasião em que elaborara um Programa de Revisão da Constituição Federal de 1891.

Fizera-o a pedido do capitão Juarez Távora que lhe dissera: "há um ano estamos governando sem saber como. Queria que nos elaborasse um programa de ação". ${ }^{3}$

O próprio Oliveira Vianna, comentando sua contribuição, dissera: "Minha impressão é que não agradou. . . Muita coisa, porém, nela sugerida, como se verá, foi realizada, ou na Constituição de 1934, ou na Constituição de 1937, ou na Constituição de 1946. ..". 4

Juarez Távora, pouco antes de falecer, acabara de publicar os seus três volumes de "Memórias". O nome de Oliveira Vianna, e o episódio da encomenda daquele programa, não são mencionados uma vez sequer naquela obra. . . Por ora, desconhece-se totalmente a motivação psicológica de Juarez em omitindo esses dados históricos. A não ser que tivesse tais fatos como óbvios, eis que reiterados na edição de 1974 dos "Problemas de Política Objetiva", estando vivo ainda Juarez e em plena atividade de memorialista.

3. Depois de uma vigência atribulada de 43 anos, a Constituição Republicana de 91 viria a ser substituída por outra em 16 de julho de 1934.

A elaboração dessa Constituição ficou a cargo de uma Assembléia Nacional Constituinte convocada pelo Governo Provisório e Revolucionário de Getúlio Vargas, segundo o Decreto $\mathrm{n}^{\circ}$ 21.402, de 14 de maio de 1932. As eleições gerais seriam realizadas a 3 de maio de 1933. No mesmo ato criou-se uma Comissão destinada a elaborar o anteprojeto que o Governo iria oferecer à Constituinte como base dos trabalhos desta.

A $1 .^{\circ}$ de novembro de 1932 , pelo Decreto $n .^{\circ} 22.040$, visando fazer acelerar os trabalhos dessa Comissão, regulamentaram-se os seus trabalhos.

4. A Comissão passou para a história como sendo a "Comissão do Itamarati".

o Presidente nato seria o Ministro da Justiça, então Antunes Maciel. A Presidência efetiva entretanto foi exercida por Afrânio de Mello Franco, o Ministro das Relações Exteriores e as primeiras reuniões foram realizadas na própria residência do Ministro Presidente. 
5. Demais elementos integrantes: José Américo de Almeida, Antônio Carlos, velho liberal mineiro, João Mangabeira, com nascentes idéias socialistas, Agenor de Roure, o constitucionalista, Prudente de Moraes, Artur Ribeiro, representante do Judiciário, Oswaldo Aranha cujas recentes biografias omitiram totalmente a brilhante e inesperada participação que teve nos trabalhos, Carlos Maximiliano, o respeitado jurista sul-rio-grandense, Góis Monteiro, representando o pensamento dos tenentes, Temístocles Cavalcanti, administrativista e futuro integrante do Supremo Tribunal Federal e Assis Brasil, que jamais compareceu às reuniões.

6. A participação de Oliveira Vianna era permanente e ativa, requerendo, sugerindo, oferecendo emendas e substitutivos.

Foi classificado como membro da subcomissão encarregada de redigir o capítulo inédito nas nossas Constituições - "Família, Educação, Ordem Econômica e Social".

Participavam dessa subcomissão João Mangabeira e José Américo de Almeida.

7. Os debates preliminares na Comissão do Itamarati, como o seriam os debates na própria Assembléia Constituinte, revelam à saciedade o comparecimento das modernas idéias de organização dos órgãos estatais e o problema fundamental decorrente da ineficácia da Constituição de 91. Assim sendo, anotam-se quatro temas básicos na discussão e na solução dos constituintes: o da Federação, o da Representação Classista, e dos Conselhos Técnicos como órgãos de cooperação dos organismos governamentais e a definição de uma ordem econômica e social para o país.

8. Salvo raras exceções, era pacífica a adoção da representação mista junto ao Poder Legislativo: e o texto que veio a se transformar no artigo 23 da Constituição trazia esta curiosa redação - "A Câmara dos Deputados compõe-se de representantes do povo [...] e de representantes eleitos pelas organizações profissionais ......" (grifos meus), e em que se distinguem como sendo do "povo" os advindos dos partidos (...) e os demais...

Obras de direito ou de história costumam atribuir a Oliveira Vianna a idéia fundamental e o seu radicalismo a respeito da representação profissional. $O$ estudo das atas da Comissão do Itamaraty revela: a) a idéia estava generalizada, sendo apenas Oliveira Vianna aquele que, mais demoradamente, escrevera a respeito; b) a moderação da posição do mesmo, pretendendo uma gradativa adoção do princípio, ao contrário de outros e ao contrário do que, afinal, veio a ser inscrito na nova Constituição.

9. Sessão histórica realiza a Comissão do Itamarati a $1 .^{\circ}$ de dezembro de 1933 quando se definem as posições a esse respeito. Registra a ata o espírito reinante na Comissão, procurando acomodar as várias tendências aí assentes, verbis:

O Sr. Presidente[...] e indaga de Sr. Mangabeira se trouxe a redação da forma conciliatória das diversas opiniōes emitidas. ${ }^{5}$

João Mangabeira responde afirmativamente e passa a ler o texto que elaborara.

A seguir, Oswaldo Aranha suscita a preliminar de estabelecer-se se deverá, ou não, haver representantes classistas na Assembléia Nacional. Logo é Agenor de Roure quem lê sua declaração de voto. 
Oliveira Vianna, então, assim se posiciona: pensa que se deva começar pelo início em matéria de representação política das classes, estabelecendo-a nos Municípios. Depois, nos Estados. Só então que se pense em levá-la à esfera federal. Pensa assim porque previamente se deverá organizá-las profissionalmente. E isso não é obra de lei, mas "do tempo, da evolução econômica, do trabalho lento das forças sociais e espirituais". 6 Sendo o Brasil o país da insolidariedade e da ausência do espírito de associação, não se conseguirá modificá-lo por decreto como num passe de mágica. Instituir a representação profissional antes de sua organização será criar artificialismo e falsidade.

Não se improvisa a solidariedade de uma classe, não se improvisam o sentimento e o hábito de cooperação, o espírito sindicalista, a organização corporativa. ${ }^{7}$

Adotá-lo seria cair no erro de 1891, quando se criou o artificialismo de falsos municípios e falsos Estados... Assim, é preciso ensaiar essa representação, modestamente, iniciando-a pelos Conselhos Municipais. ${ }^{8}$

As classes são realidades naturais - e a sua marcha para a integração obedece às leis naturais, sobre as quais a ação consciente dos legisladores e estadistas tem uma influência muito reduzida.?

Votam contra a representação classista: Antônio Carlos, Prudente de Moraes, Arthur Ribeiro e Afrânio de Melo Franco.

Apóiam a representação mista: João Mangabeira, Oswaldo Aranha, José Américo, Góis Monteiro e Carlos Maximiliano que adota inteiramente a posição moderada de Oliveira Vianna.

Themístocles Brandão Cavalcanti é favorável a uma Assembléia integralmente classista.

\section{Documentos}

\section{CONSTITUIÇÃO DE 1934}

\section{DO PODER LEGISLATIVO}

Art. 22 - O Poder Legislativo é exercido pela Câmara dos Deputados com a colaboração do Senado Federal.

Art. 23 - A Câmara dos Deputados compõe-se de representantes do povo eleitos, mediante sistema proporcional e sufrágio universal, igual e direto, e de representantes eleitos pelas organizações profissionais na forma que a lei indicar.

$\S 3 .^{\circ}$ - Os Deputados das profissões serão eleitos na forma da lei ordinária por sufrágio indireto das associações profissionais compreendidas para esse efeito, e com os grupos afins respectivos, nas quatro divisões seguintes: lavoura e pecuária; indústria; comércio e transportes; profissões liberais e funcionários públicos. 


\title{
DA COORDENAÇÃO DOS PODERES
}

Art. 88 - Ao Senado Federal, nos termos dos arts. 90, 91, e 92, incumbe promover a coordenação dos poderes federais entre si, manter a continuidade administrativa, velar pela Constituição, colaborar na feitura das leis, e praticar os demais atos da sua competência.

\section{DOS ÓRGÃOS DE COOPERAÇÃO NAS ATIVIDADES GOVERNAMENTAIS DOS CONSELHOS TÉCNICOS}

Art. 103 - Cada Ministério será assistido por um ou mais Conselhos Técnicos, coordenados, segundo a natureza dos seus trabalhos, em Conselhos Gerais, como órgãos consultivos da Câmara dos Deputados e do Senado Federal.

$\S 2 .^{\circ}$ - Metade, pelo menos, de cada Conselho será composta de pessoas especializadas, estranhas aos quadros do funcionalismo do respectivo Ministério.

$\S 4 .^{\circ}-\bar{E}$ vedado a qualquer Ministro tomar deliberação, em matéria de sua competência exclusiva, contra o parecer unânime do respectivo Conselho.

\section{Pronunciamento de Oswaldo Aranha, a 1. ${ }^{\circ}$ de dezembro de 1933:}

As classes existiram, no Brasil, talvez antes de qualquer outra organização política. No Brasil devia-se - e infelizmente não se o pode conseguir desde já - caminhar para o Estado Corporativo, ou seja, fazer justamente que o voto se torne a expressão de mais de um. Se na primeira eleição não houver a consciência plena do voto do operário, na segunda já haverá um pouco mais. A representação das classes na Assembléia Nacional será uma grande coisa para melhorar os costumes políticos, para influenciar no espírito do voto. O indivíduo precisa estar certo de que vota no seu partido, na sua classe; de que, no mesmo dia em que elege o deputado da circunscrição elege também o representante de sua classe. Entre as coisas que se vê e as que não se vê, estas muitas vezes deliberam mais do que aquelas. As influências da religião, do sentimento de pátria ou de família, estabelecem uma união entre o voto do orador e de seus colegas e de outros. Entre os burgueses dois banqueiros são inimigos e, ainda quando devam representar o mesmo interesse, se combatem no conflito das ocorrências; mas têm o sentimento comum da pátria, da família, da religião. Assim como há entre os burgueses o sentimento da pátria, da família, da religião, que os une, há também entre os proletários, e, mais do que isso, o estado natural deles. Existe uma solidariedade de pedreiros, ferreiros e carpinteiros maior do que entre três advogados.

[Atas da Comissão Elaboradora do anteprojeto da Constituição de 1934, in Elaborando a Constituição, José Affonso Mendonça de Azevedo, s/ed., Belo Horizonte, 1933, p. 349.]

\author{
Departamento de Propedêutica Jurídica \\ Pontifícia Universidade Católica \\ Porto Alegre - Brasil
}




\section{NOTAS}

1 Afonso Arinos de Mello Franco, Um estadista da República (Rio de Janeiro: José Olympio, 1955), v.III, p.1410: “[...] e então se verá como muito do bom e muito do mau da organização política brasileira, desde então até à lei magna vigente, tem a sua origem nos debates daquela Comissão".

${ }^{2}$ Pontes de Miranda, Comentários à Constituição (Rio de Janeiro: Ed. Guanabara, s.d.), p.7.

3 Day de Almeida, "Oliveira Vianna dita normas" in Oliveira Vianna, de Vasconcellos Torres (Rio de Janeiro: Freitas Bastos, 1956), p.181.

${ }^{4}$ J. F. de Oliveira Vianna, Problemas de politica objetiva (Rio de Janeiro: Record, 1974), p.179.

5 José Affonso Mendonça de Azevedo, Elaborando a Constituição Nacional (s.ed: Belo Horizonte, 1933), p.338.

6 Id., ibid., 341-46.

${ }^{7}$ Id., ibid.

${ }^{8}$ Id., ibid.

${ }^{9}$ Id., ibid. 